\title{
Model of Determining the Expectations Gap between the Status Quo and Desired Status of Tourism Industry Based on Cultural Indices
}

\author{
Dr. Esmaeil Kavousy (Corresponding author) \\ $\mathrm{PhD}$ in Cultural management at Science and Research Branch \\ Islamic Azad University, Tehran, Iran \\ E-mail: fashira.unique@gmail.com \\ Dr. Ramezanali Royaei \\ Faculty member at Science and Research Branch \\ Islamic Azad University, Tehran, Iran \\ Alireza Ebrahimpour \\ $\mathrm{PhD}$ student in cultural management at Science and Research Branch \\ Islamic Azad University, Tehran, Iran
}

Received: February 9, 2011 Accepted: February 23, 2011 doi:10.5539/ass.v7n7p75

\begin{abstract}
This article aims to study the expectations gap between the status quo and desired status of tourism industry based on cultural indices in public and private sectors in Iran and present a model for determining such expectation gap. It initially deals with the most common definition of tourism and reviews types of tourism and travel incentives in Iran, and then introduces the research conceptual model based on the theory of Edgar Schein.

The results from the study shows that there is a meaningful and deep difference and deviations in the expectation gap between the status quo of tourism industry and the desired status in the future prospects of this industry in the country and it is better to offer some practical solutions to reduce the distance or fill the gap between these two statuses.
\end{abstract}

Keywords: Tourism industry, Expectation gap, Status quo and desired status of tourism, Cultural indices

\section{Introduction}

The tourism industry is one of the largest industries in the world, and despite recent events that have made its operating environment more complex, the industry continues to grow (Theobald, 2005). Tourism has been one of the world's fastest growing industries, and there are large societies entirely dependent upon the visitor for their sustenance (Note 1). Tourism is the world's largest industry. It sustained 120 million jobs in 1995, accounting for $7 \%$ of the global workforce. It is estimated that the number of international travelers in 1994 will double to 1 billion by 2010 , and $80 \%$ of tourists come from the 20 richest countries (The Hutchinson Encyclopedia).

The impact of tourism is extremely varied. On one hand, it plays an important and certainly positive role in the socio-economic and political development in destination countries by, for instance, offering new employment opportunities. Also, in certain instances, it may contribute to a broader cultural understanding by creating awareness, respecting the diversity of cultures and ways of life. On the other hand, as a tool to create jobs, it has not fulfilled its expectations. At the same time, complaints from tourist destinations concerning massive negative impacts upon environment, culture and residents' ways of life have given rise to a demand for a more sustainable development in tourism (Note 2).

In this study, it is tried to present a model to identify and determine the expectations gap between the status quo of tourism industry and the desired status in the future prospects of this industry based on the cultural indices in public and private sectors originating from the principles, concepts and management tools so that could result in 
an improved planning and management in the tourism industry of the country based on the cultural indicators and a developmental transformation in this industry.

\section{Definition of Tourism}

The definition of tourism depends upon many conditions and criteria. The reason that there is not a common definition among scientists lies in the nature of tourism and how it is viewed by individuals. However the commonest definition is that "tourism comprises the activities of persons traveling to end and staying in places outside their usual environment for not more than one consecutive year for leisure, business and other purposes" (Note 3)

\section{Types of Tourism and Travel Incentives in Iran}

1) Ecotourism: (also known as ecological tourism) is travel to fragile, pristine, and usually protected areas that strives to be low impact and (often) small scale. It is also known as Geotourism which is "best practice" tourism that sustains, or even enhances, the geographical character of a place, such as its culture, environment, heritage and the well-being of its residents (Wikipedia). Iran, considered as among the top 10 countries in terms of cultural and historical tourism attractions, is definitely listed as the top five nations in terms of ecotourism potentials. Enjoying a rich diversity of weather conditions and ecosystems such as seas, deserts and mountains which provide potentials for skiing, rock climbing and many other activities, the country's ecotourism capacities are unique (Note 4).

\section{Location}

Iran is situated in south-western Asia and borders the three CIS states, the Republic of Armenia, the Republic of Azerbaijan, and the Republic of Turkmenistan, as well as the Caspian Seas to the north, Turkey and Iraq to the west, the Persian Gulf and the Gulf of Oman to the south and Pakistan and Afghanistan to the east.

\section{Landscape}

A series of massive, heavily eroded mountain ranges surround Iran's high interior basin. Most of the country is above 1,500 feet, one-sixth of it over 6,500 high. In sharp contrast are the coastal regions outside the mountain ring. In the north, the 400-mile strip along the Caspian Sea, never more than 70 miles wide and frequently narrowing to 10 , falls sharply from the 10,000 -foot summit to 90 feet below sea level. In the south, the land drops away from a 2,000 foot plateau, backed by a rugged escarpment three times as high, to meet the Persian Gulf and the Gulf of Oman.

\section{Mountains}

The Zagros range stretches from the border with the Republic of Armenia in the north-west to the Persian Gulf, and then eastward into Baluchistan. As it moves southward, it broadens into a 125-mile-wide band of parallel, alternating mountains lying between the plains of Mesopotamia and the great central plateau of Iran. It is drained on the west by streams that cut deep, narrow gorges and water fertile valleys. The land is extremely hard, difficult to access, and populated largely by pastoral nomads.

The Alborz mountain range, narrower than the Zagros but equally forbidding, runs along the Zagros but equally forbidding, runs along the southern shore of the Caspian to meet the border ranges of Khorassan to the east. The highest of its volcanic peaks is 18,600-foot, snow-covered Mt. Damavand. On the border of Afghanistan, the mountains fall away, to be replaced by barren sand dunes.

\section{Deserts}

The vast deserts of Iran stretch across the plateau from the north-west, close to Tehran and Qom, for a distance of about 400 miles to the south-east and beyond the frontier. Approximately one-sixth of the total area of Iran is barren desert.

The two largest desert areas are known as the Kavir-e-Lut and the Dasht-e-Kavir. Third in size of these deserts is the Jazmurian. It is often said that the Kavir-e-Lut and Dasht-e-Kavir are impossible to cross except by the single road which runs from Yazd to Ferdows, but in recent years, heavy trucks and other vehicles have travelled over long stretches of these deserts which contain extensive mineral deposits -chlorides, sulphates and carbonates and it is only a matter of time before they are exploited.

\section{Lakes \& Seas}

The Caspian Sea and the Persian Gulf are in Iran. The most important islands of the Persian Gulf on the Iranian side are: Minoo, Kharg, Sheikh Saas, Sheikh Sho'ayb, Hendurabi, Kish, Farur, Sirri, Abu Mussa, the Greater and Lesser Tunb Qeshm, Hengam, Larak, Farsi, Hormuz, Lavan, The notable ports on the Persian Gulf coast are: 
Abadan, Khorramshahr, Bandar Iman Khomeini, Mahshahr, Deilam, Gonaveh, Rig, Bushehr, Bandar Lengeh, Bandar Abbas. Other Lakes: Along the frontier between Iran and Afghanistan there are several marshy lakes which expand and contract according to the season of the year. The largest of these, the Seestan (Hamun-Sabari), in the north of the Seestan \&Y Baluchistan province, is alive with wild fowl.

\section{Drainage \& Soil}

The few streams that empty into the desiccated central plateau dissipate themselves in saline marshes. There are several large rivers, the only navigable one of which is Karun. Others are too steep and irregular. The largest rivers are: the Karun (890 km.), Sefidrood (765), Karkheh (755), Mand (685), Qara-Chay (540), Atrak (535), Dez (515), Hendijan (488), Jovein (440), Jarahi (438), Zayandehrood (405). All streams are seasonal and variable, spring floods do enormous damage, and there is little water flow in summer when many streams disappear. Water is however stored naturally underground, finding its outlet in subterranean water canals (qanat), springs and being tapped by wells.

\section{Rural Settlement}

Plain villages follow an ancient rectangular pattern. High mud walls with towers from the outer face of the houses, which have flat roofs of mud and straw supported by wooden rafters. In the open centre of the village is an occasional mosque, sometimes serving as a school, too.

Caspian villages are completely different. Here, where there is an abundance of water, the scattered hamlets have two-story wooden houses, frequently built on pilings, with a gallery around the upper floor. Separate out-buildings (barns, hen-houses, silk worm houses) surround an open courtyard (Kavousy et al., 2009).

\section{Urban Settlement}

Urban settlement has a long precedent in Iran. At present, around 50 per cent of the population lives in the big and medium-size cities. The biggest city of all is the capital, Tehran. Other big cities are Mashad, Shiraz, Rasht, Isfahan, Tabriz, followed by the medium-size cities like Ahvaz, Saari, Kermanshah, Hamedan, Kerman, Yazd and others. Traditional architecture and town planning have undergone notable changes in the last few decades. The European designs have largely replaced the old ones. Nevertheless, old buildings are still around in the medium-size cities, but fewer can be found in the big ones (Note 5).

2) History \& Architecture Tourism: With a history of thousands of years, Iranian architecture has appeared as a variety from peasant huts, teahouses and garden pavilions to some of the most beautiful and majestic structures the world has ever seen.

In fact, available materials dictated major forms. Since antiquity, Iranians compressed primitive pise-molded mud as solidly as possible and allowed to dry heavy plastic earth, tenacious gypsum mortar, bricks, stones, etc. They have formed large, well-defined masses whose broad plain surfaces invite ornamentation.

Even after more than 3000 years, certain design elements of Iranian architecture persisted. Those elements consist of high-arched portal set within a recess, columns with bracket capitals, columned porch or talar, a dome on four arches, a vast ovoid arch in the entrance, a four-eyvan courtyard, early towers reaching up toward the sky, an interior court and pool, an angled entrance and extensive decorations.

In addition to the influence of climate, available material, religious purpose and peripheral cultures, patrons also played a decisive role in the development of architecture.

The landscape itself, huge snow-capped mountains, valleys large as provinces and wide shining plains required constructions conceived and executed in terms of grandeur. Mountains were both physically and symbolically sources of inspirations in Iranian architecture.

From Zoroastrians time, the beautiful was integrally associated with light. In Iranian art, both lightness and clarity are sought and, conversely, the obscure and confused are avoided.

Beauty for ancient Iranians, like for any other ancient civilizations, was an attribute of the divine.

\section{The Development of Persian Architecture}

Farming hamlets dating from 8000-6000 B.C. have been disclosed as referred to as the necessary predecessors of Persian architecture. From the fifth millennium, at Sialk historical mounds, huts started to be made. In the next stage, bricks and mud mortars and painted rooms appeared. Cone mosaics and colored and glazed bricks were later used in huge ziggurats.

Elamite architecture was generally of unfired brick, with red bricks used for revetment. Few centuries before Medes, in the northwest, cities had double, even triple stonewalls. Very thick and very high buildings seem to 
have been wooden, square, tower-like structures, with columns which may have been tree trunks (Achaemenian Architecture, Seleucid Architecture \& Parthian \& Sassanian Architecture).

\section{Post-Islam Architecture in Iran}

It was in the post Islam era that Sassanians' powerful forms of architecture were refined and developed.

So, the potentials of Iranian architecture were developed into the architecture of exceeding beauty. The result was to be higher, more sensitive, more varied and more expressive than its antecedents.

The priority in post-Islam era's architecture went to mosque building. Mosques were intended to stand strongly for ages. That is why they have always been the most reinforced and strengthened buildings in Islamic architecture.

Mosques started to be built in two major forms:

1) Mosques with prayer galleries full of pillars, and

2) Smaller mosques consisting of a domed chamber.

Iranians focused their efforts on reviving their own heritage of architecture like barrel vaulting, crenellated roofs, conical squelches, big bricks, oval arches, etc. Brickworks in the form of different motifs and sometimes plasterworks over bricks were characteristics of the Persian architecture of the early post-Islam period. Various kinds of mausoleums, tomb towers and specially minarets started to be built (Seljuk Architecture, Ilkhanid Architecture, Timurid Architecture, Safavid Architecture, Zand Architecture \& Qajar Architecture) (Note 6).

3) Social Tourism: Social tourism aids mobility and enables off-season tourism to be developed, particularly in regions where tourism is highly seasonal. Accordingly, social tourism encourages the creation of longer-lasting employment opportunities in the tourism sector, in line with the Lisbon Strategy, by making it possible to extend such jobs beyond the respective peak season (Note 7).

4) Cultural Tourism: Iran's art, language and literature, cinema, music, architecture, religion and sports are what make Iran's cultural tourism.

5) Entertaining Tourism: Entertainment and amusement tourism is when a person wants to travel for no particular purpose, but only for fun. We are entering an age when entertainment touches every aspect of our lives. You can find entertainment not only at the theater, but also at hotels, restaurants and shopping malls, not only on television and radio, but also on web sites and cellular phones. So, it's important to keep this trend of tourism going (Kavousy et al., 2009).

\section{Research Goals}

\section{Ideal Goal}

Doing research that could result in an improved planning and management in the tourism industry of the country based on the cultural indicators and a developmental transformation in this industry.

\section{Main Goal}

Presenting a model to identify and determine the expectations gap between the status quo of tourism industry and the desired status in the future prospects of this industry based on the cultural indices in public and private sectors originating from the principles, concepts and management tools.

\section{Sub-Goals}

1 - Identifying cultural dimensions, components and indicators of tourism in the country.

2 - Determining the importance (weighting) of the cultural dimensions, components and indicators of tourism in the country.

3 - Identifying the status quo of the tourism based on cultural indicators in the country.

4 - Identifying the desired status of tourism based on cultural indicators in the country.

5 - Designing a model to identify and determine the status quo and the desired status and determining the expectations gap between the two conditions based on the cultural indicators in the country.

6 - Providing solutions based on cultural indicators in the perspective of sustainable development in order to create methodic backgrounds to reduce the expectation gap and promote the status of tourism industry. 


\section{Research Questions}

\section{Main Question}

1. By which model the expectation gap between the status quo of tourism industry and the desired status in the future prospects of this industry based on the cultural indices in public and private sector can be determined?

\section{Sub-Questions}

1. Which are the cultural dimensions, components and indicators of tourism in the country there?

2. How important are the cultural concept, dimensions, components and indicators of tourism?

3. What is the status quo of tourism in the country based on cultural indicators?

4. What is the desired status of tourism in the country based on cultural indicators?

5. What model can be designed for measuring the expectation gap between the status quo and future prospects of tourism industry based on cultural indicators in the country?

6. What strategies can be presented to promote the tourism industry with respect to cultural indicators?

\section{Research Hypotheses}

Considering that the researcher is seeking to design and provide a model for determining the expectations gap between the status quo and future prospects of tourism based on the cultural indicators, the model in this study reflect the status quo and the status ahead and exegetes the expectations gap between those two statuses and the reasons for such gap are considered as the research hypothesis and the main source of the research and consequently after designing the given model, testing it constitutes the research hypotheses.

\section{Research Method}

Different methods exist for the research and each fitting the subject and nature of research in the field of humanities is valuable.

This method of this research is descriptive and in terms of objective, considering the extent and the importance of tourism for the country and its relationship with culture, it is functional/ strategic. To describe the data, the central indicators and distribution is used.

\section{Research Scope}

Considering that identifying the topic and domain of the research is crucial in field researches, therefore, the subject and place domain of study is as follows:

\section{Subject Scope}

The subject of this research is in the field of tourism studies and cultural management.

\section{Spatial Scope}

The spatial realm of this study includes basic levers and founder of tourism in the country such as the Organization of Cultural Heritage, Handicrafts and Tourism Organization as public sectors and tourism and leisure centers of Oppressed Foundation and Travel and Tourism Agencies Union as the private sectors.

\section{Statistical Population \& Sample}

Statistical population is the generalization field of results and findings from the research and sample units include all people selected by the researcher to review.

The statistical population in this research includes Cultural Heritage Organization; Tourism and Handicrafts Industry with 250 people (in Tehran), tourism and leisure centers of Oppressed Foundation and Travel and Tourism Agencies Union with 1300 people (in Tehran). Analysis Unit and the Witness Unit include cultural experts and professionals and responsible and policy makers in tourist areas in both public and private sector.

\section{Data Collection and Analysis Methods}

To collect data in this study two methods of library and field / survey are used. For analysis and obtaining results from the data collected in this study with regard to the research method, a series of statistical techniques have been used; for example in the regulation of information and data and graphical display, circular and linear charts, histogram and some other most frequently used statistical tools and techniques available in the collection of statistical software for social sciences (spss) and (mathlab) were applied. To describe the data, the central and dispersion parameters have been used. 
To test the research questions, non-parametric tests are used. Therefore, to measure meaningful relationship between variables in research hypotheses, significant correlation coefficients and particularly, $\mathrm{T}$ test was used. Also, the comparative tables were presented to compare the status quo and desired status of tourism and finally, the model for expectations gap was offered.

\section{Research Conceptual Model}

\section{Insert Figure 1 Here}

\section{Tourism Cultural Dimensions}

\section{Insert Table 1 Here}

\section{Insert Table 2 Here}

\section{Results from Testing Hypotheses}

1. Considering the existing expectations gap, is there any difference in the expectations gap between the status quo and desired status of tourism in public and private sectors? Group Statistics

\begin{tabular}{|l|l|l|l|}
\hline Standard deviation & Score average & variable & G \\
\hline 8.44779 & 11.7500 & 68 & Private \\
\hline 6.59056 & 10.1563 & 68 & Public \\
\hline
\end{tabular}

H0: There is no difference in the expectations gap between the status quo and desired status of tourism in public and private sectors.

H1: There is a difference in the expectations gap between the status quo and desired status of tourism in public and private sectors.

As it is shown in the table above, the total of the given variables (dimensions, components and indicators) is varied in both public and private sectors (68). Despite the deviation of +-8 in the private sectors, the average is almost 12 and in the public sector with deviation of +-7 , the average is almost 10 . In other words, in the private sector, over $90 \%$ of variables have obtained the scores of 4 to 20 and in the public sector; this score is 3 to 16 .

\section{Independent Samples Test}

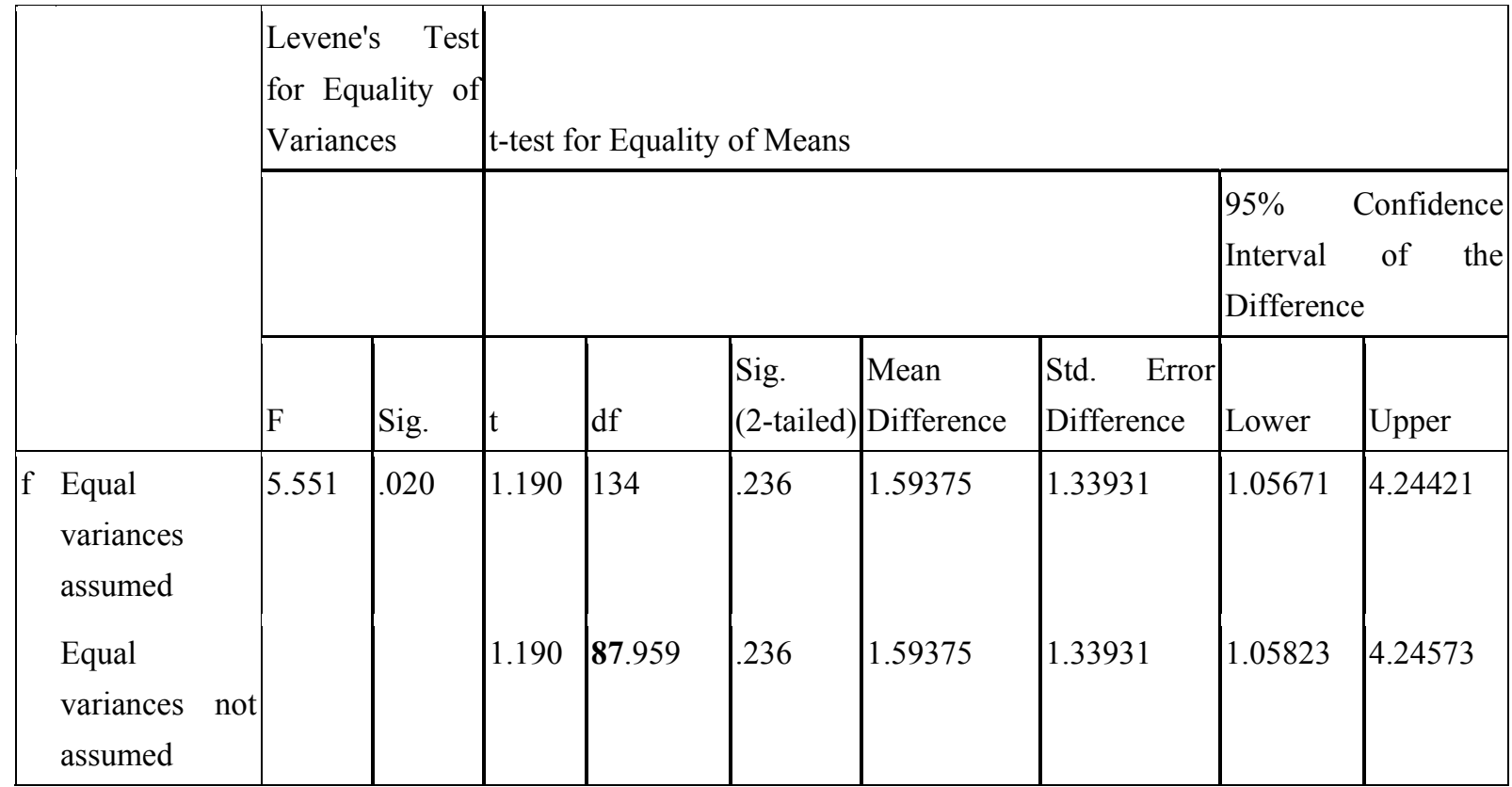

The results from $\mathrm{t}$ test and sampling (statistic test) have shown that $\mathrm{t}=1.19$ compared with critical values $\mathrm{t}=$ 1.98, degree of freedom $=134$ and the error level of five are in the scope of $\mathrm{H} 0$ and $\mathrm{H} 1$ based on the difference between the average of two communities with the error level of 5 percent is refused and with 95 percent of confidence and confirming the interval between them, it can be said that there is no significant difference in the expectations gap between the status quo and desired status of tourism in private and public sectors. 


\section{Conclusion}

This research was mainly conducted to design and present a cultural model for determining the expectation gap between the status quo of tourism industry and the desired status in the future prospects of this industry based on the cultural indices in public and private sectors originating from the principles, concepts and management tools.

The theoretical framework of this research was based on the theory of Edgar Schein which was shown in the conceptual model.

The studies and analysis conducted show that there is a meaningful and deep difference and deviations in the expectation gap between the status quo of tourism industry and the desired status in the future prospects of this industry in the country. These deviations are sometimes high in some aspects, components and indices of and less in others. So, it is better to offer some practical solutions to reduce the distance or fill the gap between these two statuses.

\section{References}

Kavousy E, Royaei R A and Ebrahimpour A. (2009). The Role of Tourism Agencies in Development of Tourism in Iran. European Journal of Social Sciences, Volume 12, Number 1.

Theobald, W. F. (2005). The Meaning, Scope, and Measurement of Travel and Tourism, in W. F. Theobald (eds), Global Tourism,3rd edition. Butterworth- Heinemann/Elsevier, New York, pp. 5-24.

The Hutchinson Encyclopedia.

WTO, 1992 - subsequently ratified by the UN Statistical Commission.

[Online] Available: http://www.un.org/esa/sustdev/csd/ngo4.pdf.

[Online] Available: http://planningcommission.nic.in/plans/stateplan/sdr_hp/sdr_hpch19.pdf.

[Online] Available: http://www.ecotour-iran.com/glance1.htm.

[Online] Available: http://www.itto.org/aboutiran/?status=countryinfo\&catid=121.

[Online] Available: http://www.destinationiran.com/Architecture.htm.

[Online] Available: http://ec.europa.eu/enterprise/tourism/major_activities/social_tourism/index_en.htm.

\section{Notes}

Note 1. http://planningcommission.nic.in/plans/stateplan/sdr_hp/sdr_hpch19.pdf

Note 2. http://www.un.org/esa/sustdev/csd/ngo4.pdf

Note 3. WTO, 1992 - subsequently ratified by the UN Statistical Commission

Note 4. http://www.ecotour-iran.com/glance1.htm

Note 5. http://www.itto.org/aboutiran/?status=countryinfo\&catid=121

Note 6. http://www.destinationiran.com/Architecture.htm

Note 7.http://ec.europa.eu/enterprise/tourism/major_activities/social_tourism/index_en.htm

Table 1. Expectations gap between status quo and desired status based on cultural dimensions of tourism in the public sector

\begin{tabular}{|l|l|l|l|l|l|}
\hline $\begin{array}{l}\text { Cultural Engineering } \\
\text { Dimensions of Tourism }\end{array}$ & Weight & Raw & $\begin{array}{l}\text { Desired } \\
\text { Status }\end{array}$ & $\begin{array}{l}\text { Status Quo in the } \\
\text { Public Sector }\end{array}$ & $\begin{array}{l}\text { Deviation from the } \\
\text { Desired Status }\end{array}$ \\
\hline Artifacts & 0.316 & 32 & 32 & 10 & 22 \\
\hline Values & 0.33 & 32 & 33 & 11 & 22 \\
\hline Fundamental Assumptions & 0.354 & 31 & 35 & 11 & 24 \\
\hline $\begin{array}{l}\text { Cultural Engineering in } \\
\text { Tourism }\end{array}$ & & 100 & 32 & 68 \\
\hline
\end{tabular}


Table 2. Expectations gap between status quo and desired status based on cultural dimensions of tourism in the private sector

\begin{tabular}{|l|l|l|l|l|l|}
\hline $\begin{array}{l}\text { Cultural Engineering } \\
\text { Dimensions of Tourism }\end{array}$ & Weight & Raw & $\begin{array}{l}\text { Desired } \\
\text { Status }\end{array}$ & $\begin{array}{l}\text { Status Quo in the } \\
\text { Public Sector }\end{array}$ & $\begin{array}{l}\text { Deviation from the } \\
\text { Desired Status }\end{array}$ \\
\hline Artifacts & 0.316 & 31 & 32 & 10 & 22 \\
\hline Values & 0.33 & 32 & 33 & 11 & 22 \\
\hline Fundamental Assumptions & 0.354 & 29 & 35 & 10 & 25 \\
\hline $\begin{array}{l}\text { Cultural Engineering in } \\
\text { Tourism }\end{array}$ & & 100 & 31 & 69 \\
\hline
\end{tabular}

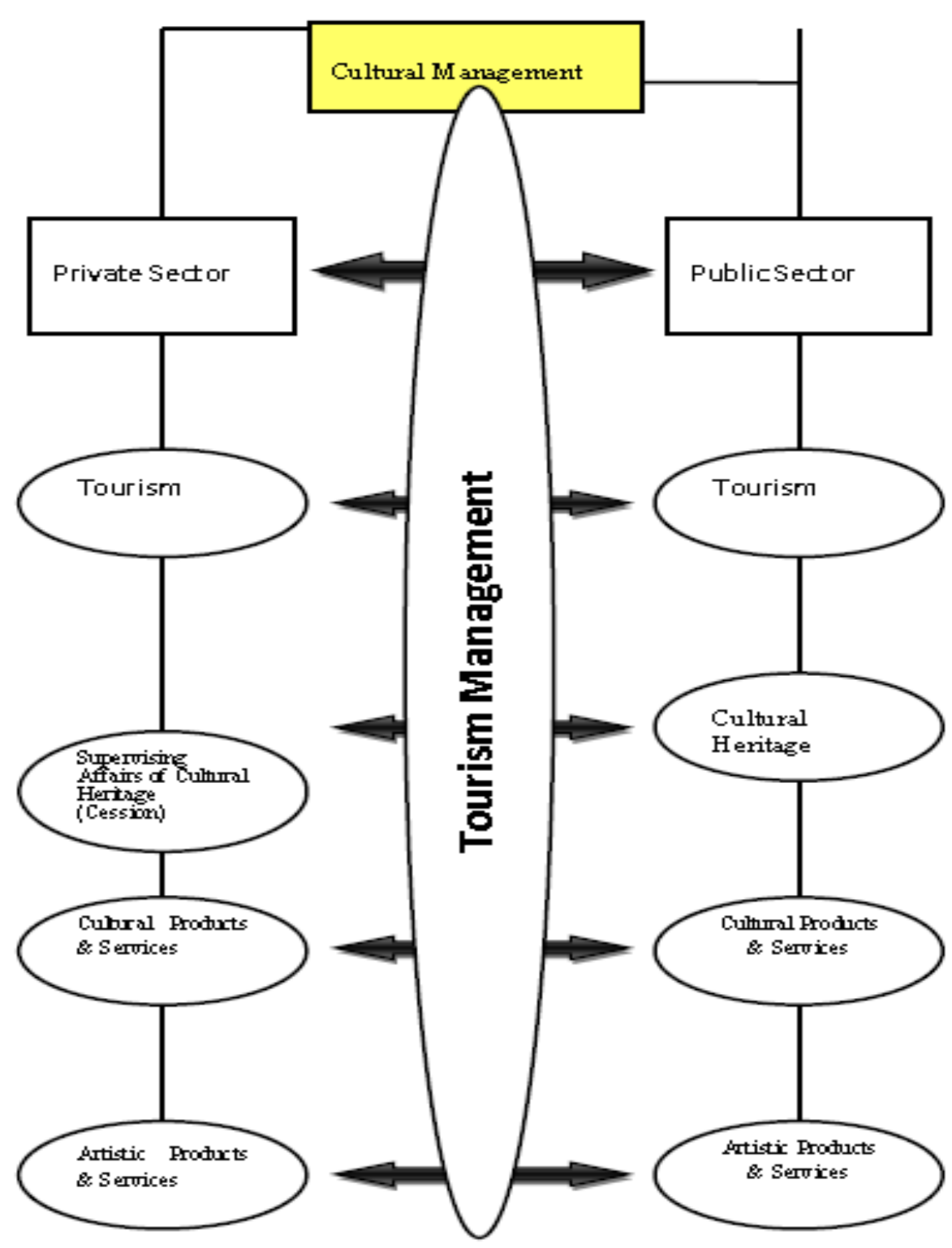




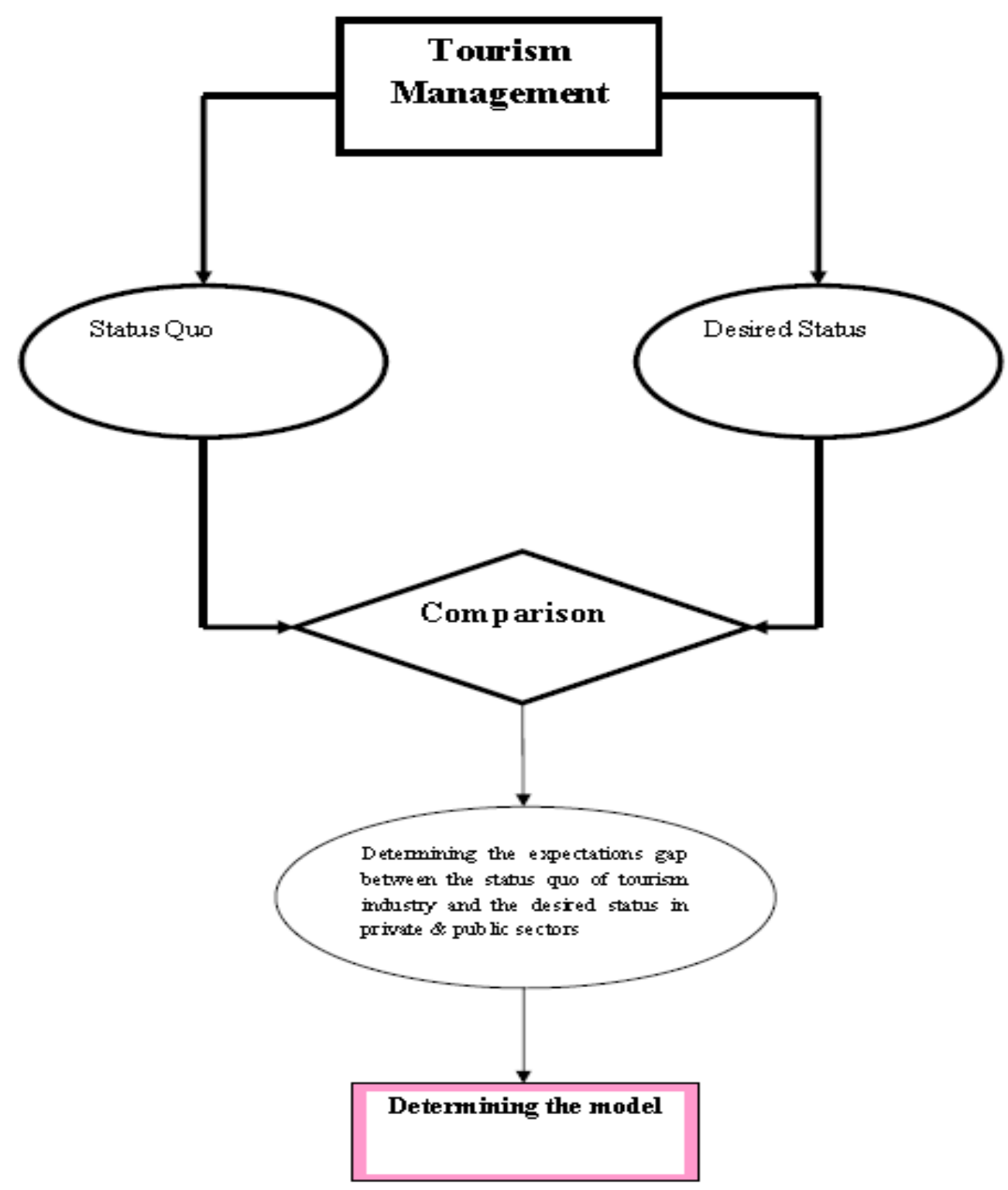

Figure 1. Conceptual model of study 